\title{
The new seismology
}

\section{Professor C. G. Knott D.Sc, F.R.S.E.}

To cite this article: Professor C. G. Knott D.Sc, F.R.S.E. (1899) The new seismology, Scottish Geographical Magazine, 15:1, 1-13, DOI: 10.1080/00369229908733018

To link to this article: http://dx.doi.org/10.1080/00369229908733018

曲 Published online: 27 Feb 2008.

Submit your article to this journal 준

III Article views: 5

Q View related articles 5 


\section{THE SCOTTISH}

\section{GEOGR A P H C A L}

\section{MAGAZINE.}

\section{THE NEW SEISMOLOGY. ${ }^{1}$}

By Professor C. G. Knotr, D.Sc., F.R.S.E.

To residents in this land an Earthquake is a rare visitant; and when, at uncertain intervals, it does make its presence felt, it is of too mild a type to attract general notice. History, however, is full of records of destructive earthquakes which overwhelm cities, annihilate islands, lay waste broad stretches of country, alter the river courses, and transform the contour of hill and dale. The mind of man, ever prone to $\mathrm{d}$ well upon the terrible and the awful, has seized on this aspect of it; and no poet would ever dream of depicting an earthquake other than a terror that both "wasteth at noonday" and "walketh in darkness." That is the old seismology. That is what we expect to read of in treatises on earthquakes and volcanoes.

But within this generation a new seismology has arisen. The destructive earthquake is no less a terror than of old, but its value as a revealer of scientific truths has grown with the centuries. The gentler earthquakes that spare the works of man are, one might almost say, welcomed by the enthusiasts who make seismology their special study. I recollect once hearing a well-known seismologist remark, when he had got an improved instrument into working order, "Now, if a good earthquake would only come along!" That was in Japan, where hundreds of earthquakes are now registered in the course of each year. And the modern development of seismology is largely due to the workers in that land of seismic activity, and especially to the scientific men from Europe and America whom the Japanese, in their thirst for Western knowledge, so warmly welcomed to their midst. Conspicuous amongst these is

1 Seismology, by Professor J. Milne, F.R.S. (International Scientific Series, vol. lxxxv. Kegan Paul and Co.)

VOL. $\mathrm{XYY}$. 
Professor John Milne, F.R.S., whose recent book has brought together, in a form accessible to all, the varied and, to a large extent, novel phenomena that are the basis of what I have called the New Seismology. In Italy also, the same subject has been studied with great eagerness; and in countries like Italy and Japan, where the earth's crust seems to be in a continuous state of commotion, seismological observatories are as necessary as meteorological or magnetic observatories. In our own land, Comrie has long been known as a locality of seismic disturbance; but the disturbances come, comparatively speaking, so seldom that it would require a century to obtain observations of a scientific value at all comparable with what may be obtained in Italy or Japan within a year.

No one of scientific inclination can reside in Japan without being impelled to become, to some extent, a seismologist. As regularly as the stroller in Princes Street looks at his watch when the time-gun fires, so did the resident in Japan draw forth his watch at the first symptom of an earthquake. He timed its advent and noted its longevity. The observation, of course, lacked much of scientific value, there being a large personal equation. Also many a small earthquake that indicated its presence to the dweller in-doors by the creaking of beams and the shaking of ornaments, passed unheeded by the man in the street. Again, alertness in detecting earthquakes varied in individuals, and even a man's position was a factor in his sensitiveness to seismic disturbances. Then stretched out on a rattan chair, or when lying in bed, one seemed to be more quickly sensible of the presence of an earthquake, than when walking, or standing, or even sitting-possibly because the body had more points of contact with the earth.

It was, in short, quite impossible for any single observer to hope to catch every earthquake that rumbled past; he might be talking, or hunting, or on a journey, or peradventure he slept too soundly even to be awakened by a fairly severe shock. Hence the necessity for instruments, for self-recording seismographs and seismometers; and once these were fairly established in sufficient numbers throughout the land, personal observations ceased to have the value they once had. Not only did these instruments record, with a precision unattainable otherwise, earthquake shocks that could be felt by man, but they gave records of still feebler tremors whose existence had hitherto escaped detection. On these records of impalpable earthquakes, accumulating with a rapidity almost beyond control, the new seismology rests.

The instrument for "forecasting" seismic disturbances has not yet been invented, so that the scientific man cannot hope to vie with the soi-disant predicter of earthquakes who claims to know by the "feel" of the air that a shock is near. One night in Japan, when parting with such a prophet, I asked, innocently enough, "Well, is there going to be an earthquake to-night?" He laughed nervously, and then felt obliged to say No. A few hours later we had one of the most lively shocks of the year! The truth is that any nervous person is as likely to feel a little "down" before an earthquake as after it; and when palpable shocks come at the rate of once a week, there is no difficulty in establishing, to 
the satisfaction of his prophetic soul, a connection between his nervous state and the earth's seismic state.

In considering briefly some of the old problems that the new seismology has, to some extent, elucidated, and in touching on the new problems that it has conjured up, I do not pretend to discuss necessarily what is of greatest importance in this branch of geological science. The importance of a new truth or new fact can be settled only as time goes on; the interest of it is largely a personal question. The tiny spark and feeble current which Faraday studied sixty-eight years ago were interesting to the few; nowadays, in telegraphs, telephones, electric lights, dynamos, and motor-ears they are of paramount importance to the world. o Naturally, then, I choose for discussion those seismological problems which are, or have been, of special interest to myself. Others will $\checkmark$ probably find a greater interest in other problems; but all who have any $\Xi$ desire to know as much as possible of the pulsations of our earth will find ample material for thought in Professor Milne's new book.

Professor Milne's Seismology is an entirely different work from his I Earthquakes, a fourth edition of which was recently published. It is - well to mention this, because a hasty glance at the opening sentence of $\approx$ the preface has led some reviewers to regard Seismology as a new edition of Earthquakes. To any one acquainted with the earlier work, a very cursory inspection of the new book will suffice to show how different they $\vec{D}$ are. The one, in fact, supplements the other.

In a rapidly progressing science like seismology it is hardly possible for an author of a book to be quite up-to-date; but Professor Milne very nearly manages so to be. On reading the book, one is impressed with the grip the author has of the most recent detailed results from all seismic districts, and with his open-mindedress in accepting observations - at their true value, even though these seem to militate against some of his own speculations. Clearly he is actuated by the one desire to arrive at the truth. There is an honesty of endeavour to get at the heart of things. There is no captious criticism of others' work, and no evading of facts which tell against his own views. On the other hand, there is no favouritism to any particular coterie of workers, and there is no mock depreciation of his own work. In singleness of mind Professor Milne sets himself to the task of unravelling a few of the mysteries of earth quiverings. If some of his early theories have proved untenable, he is the first to recognise the fact, and at once begins in the light of growing knowledge to fabricate new ones. For in pioneer work of this kind, a theory is a most fruitful centre of new lines of inquiry. Probably no living man has excelled Professor Milne in the devising and making of experiments which were intended to elucidate seismic phenomena. These are sufficiently referred to in the pages of his book to make their purpose evident.

Perhaps the most startling result of a general character which has been established is that the earth's surface is in a continuous state of movement. The slow secular changes of level have long been familiar to geologists, and these are as characteristic of districts free from volcanic or seismic disturbance as of regions where catastrophes are frequent. 
But just as the delicate seismometers, installed in Japan and Italy, proved the existence of veritable earth quakings which were too feeble to assert themselves as "shocks," so still more delicate instruments have brought to light quick tremors, gentle pulsations, and slow tiltings, not merely in so-called earthquake countries, but in every country under the sun. To study these seismic phenomena we need not leave our own shores for any distant isle of the sea. We have simply to establish our observatory far enough away from the rattle of railway trains and the din of traffic, so as to eliminate any artificial source of disturbance, and there with a sufficiently delicate instrument installed-horizontal pendulum, bifilar pendulum, tromometer, etc.-we can study the ceaseless tremblings and pulsations of our earth.

Among the various tremors and shiftings recorded on these delicate instruments, there is one type which the observer soon recognises as having had its origin in a considerable and possibly violent earthquake originating thousands of miles away. In the first edition of his Earthquakes (1883), Professor Milne wrote:-"It is not unlikely that every large earthquake might with proper instrumental appliances be recorded at any point on the land surfaces of our globe." But it was not till 1889-six years later-that this remarkable prediction was fulfilled. On April 18th of that year a somewhat curious and uncommon type of earthquake was experienced in Japan. It was my good fortune on the day in question to be engaged in conversation with the late Professor Sekiya in the seismological laboratory of the Tokyo University at the very instant the earthquake occurred. We at once rushed to the room where the self-recording instruments lay, and there, for the first time in our experience, had the delight of viewing the pointers mark their sinuous curves on the revolving plates and cylinders. At first sight it seemed as if the pointers had gone mad, tracing out sinuosities of amplitudes five or six times greater than the greatest that had ever before been recorded in Tokyo. There was not much sensation of an earthquake; indeed, after the first slight tremor that attracted our attention, we felt nothing at all, although in the irregular oscillations of the seismograph pointers we had evidence enough that an earthquake was passing. ${ }^{\text {. }}$

Now, in March of that year Dr. von Rebeur-Paschwitz (whose early death was a great loss to science) had set up two delicate instruments of the horizontal pendulum pattern at Potsdam and Wilhelmshaven, and these showed on April 18th very singular and similar disturbances. When the accounts of the Japanese earthquake reached Europe, von Rebeur-Paschwitz was struck-with its coincidence in time with the perturbations on his horizontal pendulum records. In short, at Potsdam and Wilhelmshaven direct records of a Japanese earthquake were obtained, and thus triumphantly was Milne's prediction of six years before fulfilled. Many like observations have been made since then, wherever sufficiently delicate instruments have been set up. Milne, in his

1 This account is quoted from a letter I wrote to Nature some months later (vol, xli, p. 32). 
own seismological observatory at Shide, Isle of Wight, obtains records of distant earthquakes at the average rate of about six per month.

The peculiarity of the record in these cases is that there is a preliminary stage of slight tremors, followed by a much larger and more abrupt motion. The interval between the first tremor and the maximum motion is a perfectly definite interval, depending on the distance the seismic disturbance has travelled. For example, in the record obtained at Potsdam on April 1889, the first tremor occurred thirty-three minutes before the maximum disturbance, and this is the interval which characterises European records of earthquakes that have originated near Japan. Now, on many of the diagrams of palpable earthquakes the record also. $o$ begins with preliminary tremors; but these last only for a few seconds, Fand are followed almost immediately by the heavy disturbance. As Trecorded on the Tokyo seismographs, the earthquake just referred to Đbegan thirteen minutes before the instant at which the first tracings appeared on the Potsdam horizontal pendulum record, and lasted for ten $N_{\text {and }}$ a half minutes. The Potsdam disturbance lasted for two and a half Thours. The seismograph, with its pointers scratching out lines on a $\ddot{O}_{\text {smoked glass surface was, of course, as regards sensitiveness, vastly }}$ Einferior to the horizontal pendulum, whose record was taken photographically. The seismograph would have given no indications at all at Potsdam, and the horizontal pendulum would have been set into wild $\overline{\mathrm{D}}$ commotion at Tokyo. After the big motion as recorded in the seismograph had died away, a horizontal pendulum would have continued to register movements for hours. How much sooner the horizontal pendu. J-possibly a minute or two at the most. But these initial tremors which might have been registered on adelicate instrument installed at Tokyo could Thardly be the same tremor's which first made themselves felt at Potsdam, fully 5000 miles away. Nor can we suppose the long tail of subsiding Ztremors to be capable of transmission to a great distance with an >intensity sufficient to affect an equally sensitive instrument installed there. Taking all the circumstances into account, we are probably E्đjustified in regarding the Potsdam record as produced mainly by disOturbances which emanated from the origin simultaneously with the big motions recorded on the Tokyo seismographs.

Now, the distance between Tokyo and Potsdam is 5110 miles measured along the chord, and 5560 miles measured along the arc. Assuming then that the origin of the earthquake was not very far distant from Tokyo, we find that certain tremors started by the earthquake must have travelled at a rate of 400 miles per minute, or nearly seven miles per second; that the vibrations which produced the maximum motion travelled at the rate of 110 miles per minute, or nearly two miles per second; while the most slowly moving disturbances attained an average speed of only 34 miles per minute, or fully half a mile per second.

There is an inherent difficulty in identifying corresponding parts of the records of a disturbance at two widely distant localities. Still we cannot be far wrong in regarding the maximum motions at the two places as originally identical, so that this particular type of disturbance 
travels between Japan and Europe at the rate of about two miles per second. Had the horizontal pendulum at Potsdam been of less delicate construction the preliminary tremors might have escaped notice alto. gether, and it is possible that still feebler tremors belonging to the same disturbance, but too weak for detection, reached Potsdam sooner than those that were actually observed. This consideration shows that a comparison of the times at which a particular earthquake registers its advent at various stations can be of little value unless the recording instruments are of equal delicacy. And even when that has been accomplished there is another difficulty. The first tremors recorded at the various stations are not necessarily identical. The disturbance spreads as it advances, and the energy in unit volume still further decays because of viscosity. Hence the first tremor recorded at a given station will be too weak by the time it reaches a station further removed from the origin to make itself felt there, and the first tremor recorded at this more distant station will in reality correspond not to the first tremor at the nearer station, but to a later and stronger one.

Accurate determinations of speed could be obtained if we were able to follow a particular wave or group of waves from station to station, and this will no doubt be effected when instruments of the same type and delicacy have been installed at a series of stations not too far distant from one another. If, howe ver, the stations are too far apart, it is doubtful if the form of waves of the excessive complexity met with in seismic disturbances will be persistent enough to admit of certain identification.

Clearly, then, there is still a great deal to be done; but from the results already obtained a few interesting conclusions may readily be drawn.

In the first place, it touches on the romantic to be able to study directly the effects of an earthquake 6000 miles away from its origin. And the earthquake need not be a destructive one. The disturbance of April 18, 1889, did no real damage in Japan. The waves were so slow that the pointers of the Ewing's seismograph, whose motions I had the good fortune to observe, swung to and fro through large arcs, greater far than the real to and fro motion of the ground. In fact, they ceased to act normally, but because of the comparatively slow, tilting oscillation they began to swing as pendulums set in motion by a synchronous disturbance. Professor West noticed the water in the artificial pool in his garden rising a few inches first on one side and then on the other, exactly as if the pool were being rocked gently like a photographer's developing dish. So gentle and slow was the earthquake motion that many people were unaware that an earthquake was passing.

Then, in the second place, a seismic disturbance as it travels through the earth spreads out in time, its duration at any locality increasing with the distance travelled. This may partly be explained as due to the generation of secondary waves, e.g. at surfaces of discontinuity where the primary wave gets broken up into waves of different type. But this explanation hardly meets all the facts. The evidence rather goes to show that a seismic disturbance is an excessively complex combination of vibrations, oscillations, and abrupt displacements, which pass out from the origin with very different speeds. Consequently the longer the distance 
travelled, the more separated in time will the various constituents of the complex motion be. There is distinct indication that the preliminary tremors observed at distant stations precede the main maximum disturbance by an interval which increases with the distance travelled. Also it appears (see Milne's Seismology, page 77) that the movements registered at the distant stations, besides being much feebler, are distinctly less rapid than the movements recorded at regions close to the earthquake origin. At first sight it might seem as if the individual waves were themselves drawn out into slower vibrations as they sped along. Such an idea, however, is inconsistent with all we know of the properties of wave motion. The comparative smoothness of the motion at a distant station is probably due to the stifling of the more rapid vibrations in accordance with a principle of which there are many examples in the propagation of periodic changes through a medium. The shorter the wave-length of a particular type of wave motion the quicker the decay, other things being the same. No relation of this character can, of course, be established among waves of different type. Thus, short elastic vibrations travel further and have more persistence than long quasi-elastic vibrations, such as the undulatory motion of the surface of the ground near an earthquake origin, a motion probably aided by the action of gravity (Seismology, page 90).

Finally, and closely related with this spreading ont of the disturbance, there is the question of the varions velocities indicated. From the beginning of the first tremor, registered at the distant station, to the end of the disturbance, there is, broadly speaking, a continuous state of motion. The tremors are not of uniform intensity thronghout, but show several maxima, and then give place to (or exist with) the larger motion, which tails off into tremors with similar alternations of intensity. From the earliest tremor registered at Potsdam on April 18tl, 1889, to the last trace of disturbance on that date, the speeds, varied from nearly seven miles per second to only half a mile per second.

Here, obviously, we are face to face with either distinct types of motion or distinct paths through the earth-or, possibly, with both in combination. The high velocity of seven miles per second seems to demand the assumption of very much larger coefficients of elasticity than we ever meet with when experimenting with the rocky material composing the accessible parts of the earth. There is no doubt, however, that high pressure and high temperature will have some influence on the elastic constants of a given substance; and it is quite possible that at no very great distance below the earth's surface pressure and temperature changes are accompanied by profound changes in various physical properties. This seems to be the simplest explanation of the high velocity attained by the preliminary tremors. Without committing ourselves to any very precise theory, we may regard these preliminary tremors as due to the propagation along the path of shortest time of certain elastic vibrations set up by the initial movements at the earthquake focus. These fleetest of elastic vibrations are probably of a condensational character, the velocity of propagation depending chiefly upon the resistance to compression of the material at considerable depths; 
and this resistance to compression may very easily undergo great increase under high pressure. For rocky material near the surface of the earth, the average resistance to compression is such that the speed of propagation is about two miles per second, just almost exactly the measured velocity for the large motion in the historic case already cited. This lends some support to Milne's view that the large motion is propagated along the arc. Since the speed depends on the square root of the coefficient of elasticity, it follows that the average resistance to compression of the material along the brachistochronic path is about twelve times greater than the corresponding quantity for the surface matter of the earth. The resistance to compression of wrought iron is about five times the resistance to compression of the rocks experimented with by Gray and Milne; so that, due regard being paid to the different conditions as to temperature and pressure, there is nothing extravagant in the conclusion come to.

It is impossible to determine the exact position of the brachistochronic path joining two given surface stations; but probably it does not deviate much from the path of shortest length, that is, the chord. Assuming that it is the chord, then we may make some endeavour to get at the law connecting average speed along a chord with the average depth of the chord below the surface. Professor Milne has already made some proyress in this inquiry; and in the last British Association Report of the Seismological Committee (which is compiled chiefly by him) some instructive results are given. A few of these I reproduce here, with the trifling change of kilometres into miles. These results have been deduced as averages from a great many distinct observations; and the accompanying tables give the speeds of propagation of the Preliminary Tremors and of the Large Waves between stations distant from one another $20^{\circ}, 60^{\circ}, 80^{\circ}$, and $110^{\circ}$ of arc. The lengths are in miles, the speeds in miles per second.

Propagation of Preliminary Tremors.

\begin{tabular}{|c|c|c|c|c|c|c|}
\hline $\begin{array}{l}\text { Degrees } \\
\text { of Arc. }\end{array}$ & $\begin{array}{c}\text { Jength of } \\
\text { Arc. }\end{array}$ & $\begin{array}{l}\text { Length of } \\
\text { Chord. }\end{array}$ & $\begin{array}{l}\text { Average Depth } \\
\text { of Chord. }\end{array}$ & $\begin{array}{c}\text { Average } \\
\text { Speed along } \\
\text { Arc. }\end{array}$ & $\begin{array}{c}\text { Average } \\
\text { speed along } \\
\text { Chord. }\end{array}$ & $\begin{array}{l}\text { Duration in } \\
\text { Minutes. }\end{array}$ \\
\hline $\begin{array}{r}20^{\circ} \\
60^{\circ} \\
80^{\circ} \\
110^{\circ}\end{array}$ & $\begin{array}{l}1380 \\
4140 \\
5520 \\
7590\end{array}$ & $\begin{array}{l}1370 \\
3960 \\
5080 \\
6470\end{array}$ & $\begin{array}{r}42 \\
378 \\
655 \\
1230\end{array}$ & $\begin{array}{l}1 \cdot 7 \\
3 \cdot 7 \\
5 \cdot 1 \\
6 \cdot 8\end{array}$ & $\begin{array}{l}1 \cdot 7 \\
3 \cdot 5 \\
4 \cdot 7 \\
5 \cdot 8\end{array}$ & $\begin{array}{c}0 \text { to } 4 \\
20 \\
30 \text { to } 34 \\
41 \text { to } 43\end{array}$ \\
\hline
\end{tabular}

Propagation of Large Waves.

\begin{tabular}{|c|c|c|}
\hline Degrees of Arc. & $\begin{array}{c}\text { Average } \\
\text { Speed along Arc. }\end{array}$ & $\begin{array}{c}\text { Average } \\
\text { Speed alung Chord. }\end{array}$ \\
\hline $\begin{array}{r}20^{\circ} \\
60^{\circ} \\
80^{\circ} \\
110^{\circ}\end{array}$ & $\begin{array}{l}1 \cdot 3 \\
1 \cdot 75 \\
1 \cdot 8 \\
2 \cdot 05\end{array}$ & $\begin{array}{l}1 \cdot 3 \\
1 \cdot 7 \\
1 \cdot 7 \\
1 \cdot 75\end{array}$ \\
\hline
\end{tabular}


The numbers in the column headed "duration in minutes" give the intervals for the various distances between the first tremor and the large wave. A careful comparison of these "durations" seems to dispose at once of the hypothesis that the path of shortest time for the preliminary tremors lies near the surface, that is, along the arc. For if that were so we should expect to find some simple relation between the differences of lengths of arc and the corresponding differences of durations. But, as will be seen at a glance, the preliminary tremors take $12 \pm 2$ minutes to pass over $20^{\circ}$ (60 to 80$)$ and $10 \pm 3$ minutes to pass over $30^{\circ}$ (80 to 110); and there is no reason why the tremors, if they are being transmitted through surface rocks, should pass over $30^{\circ}$ in about the same time as over $20^{\circ}$.

Let us suppose, then, that the brachistochronic path corresponds approximately with the chord, so that the longer the arc the deeper below the surface lies the course of the tremor. Now, in all cases of transmission of elastic vibrations the square of the speed varies directly as the coefficient of elasticity involved and inversely as the density. The density no doubt increases with the depth, and a greater density means a smaller speed. Consequently, to account for the greater speed along the longer chord, we must assume that the coefficient of elasticity increases very markedly with the depth. To bring out the relation let us square the speeds along the chord and set them alongside the corresponding average depths of chord as in the following table :-

\begin{tabular}{|c|c|c|c|}
\hline Average depth, & 42 & 378 & 655 \\
\hline Square of speed, & $2 \cdot 9$ & $12 \cdot 7$ & $22 \cdot 1$ \\
\hline
\end{tabular}

If we plot these numbers one against the other on section paper we find that they lie approximately on a straight line. Let us assume that the square of the speed $\left(v^{2}\right)$ is expressible linearly in terms of the average depth of chord $d$, thus:-

$$
v^{2}=\mathrm{V}^{2}+\mathrm{l} d
$$

where $V$ is the speed at the surface, and $\eta_{i}$ a constant measuring the rate at which $v^{2}$ increases with the depth. Then, applying the method of least squares to the tabulated numbers, we get $V^{2}=2.9$ and $k=026$, so that finally

$$
v^{2}=2 \cdot 9+\cdot 026 d
$$

Using the values of $d$ in the table, we find for the calculated values of $v^{2}$ the numbers :-

\section{$\begin{array}{llll}4 & 12 \cdot 7 & 19 \cdot 9 & 34 \cdot 9\end{array}$}

which, under the circumstances, are in fairly satisfactory agreement with the actual values.

For considerable depths the second term of the formula becomes of comparatively small importance, so that as the depth increases the formula I have given approximates to Milne's statement that the speed varies as the square root of the average depth. 
In this investigation there is one step that is not above criticism; but until more observations are to hand it would be waste of labour to attempt to get a truer estimate of the average speed along a chord. Milne uses what he calls the "average depth" of chord; and I have simply taken his numbers in the calculation just made. But, guided by the approximate result obtained above, we should work out $a b$ initio the brachistochronic problem: to find the path of shortest time between two given points on the earth's surface, assuming the square of the speed to be a linear function of the depth.

The conclusion arrived at is, however, of great interest. It means that the square of the speed increases at a rate of nearly 1 per cent. (more accurately 0.9 per cent.) per mile of descent into the earth. Now the square of the speed is measured by the ratio of the coefficient of elasticity to the density. If we assume the density to increase steadily from its surface value we find, in order that the mean density may be $5 \frac{1}{2}$ times that of water, that this rate of increase is about $\frac{1}{36} \sigma^{\text {th }}$ per mile descent, that is, 0.28 per cent. Hence the coefficient of elasticity which determines the transmission of the preliminary tremors increases at the rate of nearly $1 \cdot 2$ per cent. per mile descent.

I chose originally the particular law of density made use of here simply because of its adaptability to calculation; but for moderate depths, say to 1200 miles, the densities measured according to the formula

$$
\text { density }=2 \cdot 75+\cdot 0028 \times \text { depth in miles. }
$$

agree to the second significant figure with the densities according to Laplace's historic but less convenient formula. At 2000 miles depth the two formula give almost exactly the same value. At greater depths the values diverge considerably, the Laplace value being the smaller. These relations may be easily shown by developing Laplace's formula in ascending powers of the depth.

Turning now to the propagation of the large waves, we notice that there is nothing like the same increase of speed, as the are is taken larger. There seems, however, to be no sufficient reason for the speed, as measured along the arc, to increase even at the rate indicated. The results tell rather in favour of the view that here also we are dealing with brachistochronic paths coinciding more or less approximately with the chord. The very slow increase of speed along the chord, as the chord is taken longer and therefore deeper, shows that the coefficient of elasticity, which determines the propagation of the large waves, increases comparatively slowly with the depth - in fact, only at a slightly greater rate than the density. This need in no way surprise us; for the great difference in the rates of propagation of the preliminary tremors and the large waves demonstrates clearly enough that different coefficients of elasticity are involved. The usual view is that the preliminary tremors correspond to what would be called compressional waves in an isotropic solid; and the large waves to distortional waves. The coefficient which determines the speed of the compressional wave involves both the elastic constants-namely, the resistance to compression and the resistance to distortion; the coefficient for the distortional wave involves only the 
latter. Now, it is quite conceivable that an increase of pressure may influence the resistance to compression to a marked degree, and yet have a comparatively slight effect on the resistance to distortion. That this really is so seems to me to be almost demonstrated by the seismological facts we have been considering.

Since the values of the large waves' velocities are but slightly influenced by change in average depth, it follows that the path of shortest time coincides very closely with the path of shortest distance. The divergence of the brachistochronic path from the chord will be much more pronounced in the case of the preliminary tremors.

There is no doubt that an earthquake is the source of different types of motion or disturbance, each type travelling outwards as a succession of waves. For simplicity, suppose that each wave of disturbance starts as a sphere. Then, so far at least as the preliminary tremors are concerned, this originally spherical wave-front extends most quickly in the direction of the eartli's centre, and most slowly in the opposite direction. Each part of the wave-front advances with a speed which is determined by its depth below the surface. The originally spherical wave-front becomes an oval drawn out in the direction of the earth's centre. A figure showing roughly the forms and distribution of the successive positions of the wave-front is given on page 123 of Seismology, where Dr. A. Schmidt's views are discussed. The paths of the vibrations are orthogonal trajectories to these wave-front surfaces-that is, they cut the successive "coseismal " or isochronous surfaces everywhere at right angles. These paths are not in general straight, just as, because of varying refraction, the rays that come to us from the setting sun are not straight.

Having in some detail discussed one of the new problems opened up by the new seismology, let us glance very briefly at one of the old problems. I refer to the question of seismic frequency and periodicity (chapter ix. in Milne's Seismology). The annual and semi-annual periods, which Merian, Perrey, and Mallet recognised in the early half of the century, have been fully established by more recent investigators working with infinitely fuller statistics. The time is not yet come for anything like a complete discussion of instrumental observations; but in a catalogue of nearly 9000 shocks, which occurred in Japan during eight years, Professor Milne gave us material which might profitably be discussed in relation to probable or possible periodicities. The peculiar merits of this catalogue were manifold. The time, locality, and area of disturbance of each shock were given; after-shocks of large earthquakes were carefully distinguished from independent shocks; and the earthquakes were grouped according to district-a very important classification. There never had been presented to the investigator such a mass of statistics for a limited region of the earth's surface in a form so convenient for discussion. When we wish to inquire into the existence of possible short periods, we should confine our attention to as limited a region as possible, consistent with a large enough body of statistics. As clearly shown by Professor Schuster ${ }^{1}$ in his criticism of my own paper, ${ }^{2}$ which was based 
on Milne's Catalogue, the total number of eartbquakes was not after all sufficient to warrant any very definite conclusion being drawn. The statistics I treated harmonically to tind if there was any evidence of periodicities depending on daily and monthly changes in the moon's position relatively to the earth. Any evidence in favour of the existence of such periodicities was no doubt slight, and, according to Schuster, no more than the theory of probabilities might lead us to expect if any statistics whatever were treated in the same way. While admitting the general validity of Schuster's criticism, I still think that in regard to the lunar monthly periodicities the relative prominence of the fortnightly amplitudes merits some consideration-especially in the case of the synodic month. That is to say, there is some evidence of a tendency to increased frequency of earthquakes at times of new moon and full moon. There is no doubt of the existence of lunar tidal stresses within the earth; and we might naturally expect a seismically sensitive region to respond more quickly when these stresses were at a maximum. Not, however, till a much greater body of statistics for one limited region is to hand will it be worth any one's labour to inquire again into the question. All we can say is that lunar stresses, as factors in determining earthquake frequency, are comparatively insignificant.

The old view that earthquakes were more frequent during night than during day was a conclusion based upon incomplete statistics. Instrumental records show an increased frequency, sometimes in the dayshocks, sometimes in the night-shocks-the preponderance in either interval varying in different periods. Before the construction of selfrecording instruments, earthquakes were felt more frequently during the night, not because they were more frequent, but because their presence was more readily recognised. A careful tabulation of a sufficient body of statistics has however demonstrated the existence of a periodicity in earthquake frequency isochronous with the alternation of night and day. The times of maximum and minimum vary from month to month; so that unless the earthquakes are tabulated by months as well as by hours the effect will be masked altogether. Thus the maximum frequency occurs at midnight in January, but gradually gets later as the year passes on till it occurs at noon in July. From July to December, on the other hand, the time of maximum frequency gradually gets earlier. Milne, Omori, and Davison have all worked at this subject, Davison's harmonic analysis of the statistics being of special interest. ${ }^{1}$ The diurnal period in after-shocks of large earthquakes is particularly well shown. There is, however, this peculiarity in regard to Japanese earthquakes and aftershocks. The after-shocks show a diurnal period with a marked maximum a few hours after midnight, whereas ordinary earthquakes, which are not after-shocks, have their maximum falling between 10 A.M. and noon. It is difficult to explain these apparent discrepancies. Wind velocity and changes of barometric pressure have been invoked, but it cannot be said with much success. One interesting point in regard to the effect of high winds, was brought out very clearly by Milne, who found that

1 See Philosophical Magazine, December 1896. 
tremors got specially lively in Tokyo when high winds were blowing on the other side of the mountain ranges to the west. Such observations show the necessity of taking into consideration the meteorological phenomena over a wide area surrounding a given seismic district.

A very interesting chapter in Milne's Seismology is the one headed "Slow Changes in the Vertical." This question is of paramount importance to astronomers, who must look carefully to possible small changes in the position of the piers supporting their instruments. Such fluctuating changes are observed at all astronomical observatories, and have been ascribed to various causes, such as unequal change of temperature, rise and fall of the tide, removal of load on one side by drying of the soil, slight shiftings or bendings of strata, barometric fluctuations, and so on.

Thus it will be seen that the seismologist, in his study of earth shakings, touches hands with the astronomer, the meteorologist, the elastician, the geologist; and in other directions he meets the engineer and the building constructor. The new seismology is a science still in its infancy, but already it has effected considerable progress. Milne's form of horizontal pendulum is being adopted in various parts of the world; and every year is adding to the number of stations and to the statistics that are being compiled. Professor Milne's book brings the subject very nearly up to date; how far it falls short may be determined by a comparison of its pages with the last British Association Report of the Seismological Committee.

\section{THE TRADE OF CENTRAL AND SOUTHERN CHINA.}

The great river of Central China, the Yangtze-kiang, rises in Northern Tibet, in the Tangla mountains, where Rockhill in 1892 saw the rivulets which descend to form the Murui-usu, the chief headwater of the river, in lat. $33^{\circ} 45^{\prime} \mathrm{N}$. and long. $90^{\circ} 50^{\prime}$ E. Flowing through Eastern Tibet under the name of Chin-sha, it assumes various names as it passes through Sze-chuan and Hu-pei, and is known to the Chinese as the Yangtze only for 200 miles from its mouth. It drains an area of over 650,000 square miles, the greater part of which lies within the Chinese boundary, and is accessible through the numerous tributaries of the river, which in some cases also afford means of transporting goods into the. basin of the Si-kiang.

It is in this part of China that British trade has the best openingsa concession has lately been granted to a British syndicate for mining and the construction of railways in the Yangtze basin-and therefore inquiries into the capacities of the country have been actively prosecuted, and several consular reports have recently appeared. Among these is one by Mr. F. S. Bourne, who accompanied the commercial mission sent out by the Blackburn Chamber of Commerce, ${ }^{1}$ from which the following notes are mostly taken.

1 Trade of Central and Southern China, Foreign Office, No. 458. 